\title{
De simuladores, locos y reality shows. Lecturas del delito en las ficciones sobre la Guerra de Malvinas'
}

\author{
Simulators, Crazy People, and Reality Shows. \\ Interpretations of Crime in Fictions about the Malvinas War
}

\author{
DIEGO EDUARDO NIEMETZ \\ CONICET / Facultad de Filososofía y Letras - UNCuyo \\ Argentina \\ diegoniemetz@gmail.com
}

(Recibido: O7-03-20I7; aceptado: 26 -O7-2OI7)

Resumen. Este trabajo indaga en los modos en que la cuestión de la Guerra de Malvinas [Falklands War en el mundo anglosajón] (1982) es representada en las ficciones de autores argentinos de tres generaciones diferentes. En un primer momento, $y$ a partir de ciertas polémicas entre proyectos estéticos diversos, se propone un acceso desde la dinámica generacional, siguiendo las pautas establecidas por Elsa Drucaroff en su ensayo Los prisioneros de la torre. Luego, en segunda instancia, se ensaya una lectura de las obras sobre la guerra a partir de la conceptualización del delito como instrumento crítico, según algunas ideas de Josefina Ludmer, con el objetivo de diversificar los modos de interpretación de dicho evento histórico.
Abstract. The following work investigates the ways in which the Falklands War (1982) is represented in the fictions written by Argentinean authors from three different generations. Firstly, and based on certain controversies between diverse aesthetic projects, we propose an approach from a generational dynamic, following the guidelines established by Elsa Drucaroff in her essay "Los Prisioneros de la torre" [The Prisoners of the Tower]. Secondly, the works about the War are approached from the conceptualization of crime as a critical instrument, following Josefina Ludmer's ideas, in order to diversify the methods of interpreting this historic event.
Palabras clave: Malvinas; delito; Osvaldo Soriano; Charlie Feiling; Juan Forn; Hernán Vanoli.
Keywords: Flaklands; crime; Osvaldo Soriano; Charlie Feiling;Juan Forn; Hernán Vanoli.

\footnotetext{
I Para citar este artículo: Niemetz, Diego Eduardo (20I8). De simuladores, locos y reality shows. Lecturas del delito en las ficciones sobre la Guerra de Malvinas.". Alabe 17. [www.revistaalabe.com] DOI: IO.I5645/Alabe2018.I7.5
} 


\section{Introducción}

En su ensayo Los prisioneros de la torre (2OII), Elsa Drucaroff propone como uno de los eventos históricos determinantes en la identidad de la nueva generación de escritores de postdictadura la fecha del 2 de abril de i982. La estudiosa identifica ese hito no solamente a partir de un obvio sentido de periodización histórica, estrictamente vinculado con la evolución de la cronología argentina contemporánea (una guerra es un evento histórico que siempre supone relevancia por el compromiso y sacrificio, simbólico y real, que exige de los habitantes de cada una de las partes involucradas y también, como es el caso, por las consecuencias políticas que pueda implicar), sino que identifica como fundamento de la elección las raíces mismas del conflicto social puertas adentro. Drucaroff señala que la ocupación de las Islas y el triunfalismo reinante en el conjunto social durante los primeros momentos de la Guerra, derivaron en sentimientos de enorme frustración y humillación, "no sólo por haber sido vencidos por Gran Bretaña, sino por haber creído la información escandalosamente inexacta que divulgó durante toda la guerra el gobierno argentino" ${ }_{2}$ (2OII: I7I).

El enfoque de Drucaroff es interesante porque lleva a discutir el problema colectivo de la experiencia reciente de la guerra al campo de la interacción de lo socio-histórico con lo estético. En esta línea, el problema que plantea tiene aristas múltiples y ha sido abordado por numerosos críticos y escritores ${ }^{3}$. Obviamente, lo que se agita en el fondo

\footnotetext{
${ }^{2}$ Drucaroff coincide aquí con una lectura mayoritaria de la sociedad argentina: la Junta Militar utilizó la Guerra como una posible estrategia de legitimación y de perpetuación en el poder y, el fracaso de las acciones bélicas, acarrearon su debacle final y la salida democrática en menos de un año. Este es un enfoque parcialmente verdadero. La bibliografía más reciente sobre el tema, especialmente la producida en el mundo anglosajón, insiste en enmarcar el conflicto en un contexto amplio de reacciones postcoloniales en contra de las potencias. Si bien el presente artículo gira en torno a la percepción de la Guerra desde la óptica argentina y de su captación a través de la literatura, es necesario señalar que en el caso de Gran Bretaña la utilización política de la guerra ha sido, también, motivo de análisis, fundamentalmente en torno a la capitalización política del asunto por parte del gobierno de Margaret Tatcher, en las elecciones de ig83. Sin embargo, en términos generales, la bibliografía coincide en que las repercusiones del conflicto y su persistencia en el tiempo y en la memoria colectiva han sido más moderadas en Gran Bretaña que en la Argentina, donde sigue siendo tema de debate permanentemente. En el país europeo, la producción ficcional es, cuantitativamente, mucho menor que del otro lado del océano. En la Argentina gran parte de la polémica, aunque haya otras líneas de análisis, se basa en la dualidad entre la presunta justicia del reclamo de soberanía sobre el territorio y la legitimidad de la guerra que fue encabezada por una dictadura antidemocrática y antipopular, que secuestró y asesinó ilegalmente a treinta mil argentinos. Un ensayo fundamental sobre el tema desde la perspectiva argentina, que analiza posiciones diversas y que resume muy bien lo que intentamos señalar, es Malvinas: de la guerra sucia a la guerra limpia, del filósofo León Rozitchner. El texto, que fue escrito desde el exilio y casi al mismo tiempo en que se desarrollaba la guerra en el Atlántico Sur, plantea y condena en fuertes términos la complicidad civil de toda la sociedad con la Junta Militar y enfoca la cuestion de Malvinas como continuidad genocida de la "guerra sucia" frente a las posiciones de otros sectores de la izquierda (como el Grupo de Discusión Socialista). El ensavo representa una posición que, como su propio autor deja entrever, fue minoritaria hasta definirse el resultado del conflicto armado. Una vez acabada la confrontación, con la derrota argentina consumada, esta misma lectura del conflicto fue asumida por vastos sectores que antes habían apoyado la campaña bélica. Es, además, la perspectiva encarnada mayoritariamente por los escritores y las obras aquí estudiados. Es importante aclarar, sin embargo, que aún hoy una gran masa de escritores, identificados con otros sectores del campo ideológico argentino, reivindican la Guerra y la consideran una gesta heroica.

${ }^{3}$ La propia Elsa Drucaroff, ha publicado artículos sobre el tema y también dedicó varias páginas del libro que hemos citado para referirse a la cuestión de Malvinas. Martín Kohan, uno de los escritores de las primeras generaciones de postdictadura, se ha ocupado del tema tanto en su producción ensayística (haremos algunas referencias más adelante) como en sus ficciones Dos veces junio (2002) y Ciencias morales (2007). Finalmente, Islas imaginadas. La Guerra de Malvinas en la literatura y el cine argentinos (2OI2), el completo libro de Julieta Vitullo basado en su tesis doctoral, es uno de los ejemplos recientes donde se abordan específicamente y desde una perspectiva crítica, las ficciones argentinas sobre Malvinas y que, a la vez, retoma y reaviva la actualidad del asunto en la sociedad argentina contemporanea.
} 
de este asunto es la cuestión de la narratividad como instrumento de transmisión de la materia histórica (o la determinación de la materia histórica a través de la narratividad) y el resbaloso límite de las relaciones entre historiografía y literatura, ampliamente explorado, entre muchos otros, por Hayden White en diferentes etapas de su producción.

No es objetivo de estas páginas repasar esas tan escarpadas como fértiles relaciones. Se trata, por cierto, de un esfuerzo ya realizado por la crítica en torno al tema puntual que nos interesa y en trabajos de largo aliento, que dirigieron sus esfuerzos a un análisis pormenorizado de las ficciones sobre el tema ${ }^{4}$. Nuestro objetivo es retomar la cuestión de Malvinas a través de un estudio generacional (aspecto sobre el que ya hemos avanzado en un trabajo anterior) para luego introducir el delito como instrumento de análisis de algunas ficciones sobre la guerra. En orden cronológico, según su fecha de publicación, las obras consideradas son: A sus plantas rendido un León (I986), de Osvaldo Soriano; "Memorándum Almazán” (I99I), de Juan Forn; El agua electrizada (I992), de Charlie Feiling; y, finalmente, Cataratas (2015), de Hernán Vanoli.

Se trata de un corpus que parte, como ya se dijo, de una disputa generacional para luego, una vez desmontada esa dinámica, internarse en el problema del delito. Por lo tanto, no tenemos una pretensión de análisis panorámica, sino operativa: la de explorar herramientas analíticas raramente utilizadas en la bibliografía existente e introducir en la serie, a través de ellas, a la nueva generación de escritores representada en nuestro corpus por Vanoli.

En síntesis, nuestro corpus abarca autores de tres generaciones diferentes en cuyos textos el tema de la Guerra de Malvinas aparece asociado con algún tipo de delito. Como veremos, lo delictual es un motivo transgeneracional que se desarrolla en gran parte de las ficciones referidas a Malvinas. Frente a esto, se impone una última aclaración: este artículo se propone exclusivamente analizar textos ficcionales de escritores argentinos, que han sido seleccionados en función de su representatividad de un marco más general. Nos adelantamos a señalar, por lo tanto, que queda para trabajos futuros un desarrollo más exhaustivo a través de la aplicación de las herramientas aquí utilizadas a otros autores y obras en el campo literario argentino; como así también la exploración de la utilidad de estas mismas variables (la generacional y las ficciones del delito) en fuentes de origen británico.

\footnotetext{
${ }^{4}$ Para un análisis panorámico de muchos de estos aspectos, además del libro de Vitullo mencionado en la nota anterior, remitimos a la tesis de maestría de Graciela Mantiñan, "A vos te falta Malvinas" Señales de identidad en el relato testimonial de la guerra de Malvinas (1982- 2005), que abarca gran parte de la producción testimonial sobre la guerra. A los trabajos de Martiñan y de Vitullo, podría sumarse una larga lista de artículos académicos y periodísticos más breves, que tienen por objetivo el análisis de ficciones y testimonios de Malvinas.
} 


\section{El asunto generacional, a veces suficiente (a veces no)}

En un trabajo anterior, y en línea con algunos de los planteos de Elsa Drucaroff en Los prisioneros de la torre, hemos analizado el tema de Malvinas en la literatura desde una perspectiva generacional y a partir de una polémica instalada entre dos grupos de escritores argentinos. En efecto, en esa ocasión estudiábamos dos modos de representar la Guerra en el campo cultural de los años de la postdictadura y a partir de una disidencia, surgida en ese contexto, entre los escritores "narrativistas" y los "experimentalistas" En dicho análisis, hemos procurado rastrear los modos antagónicos en que dos autores, paradigmáticos de cada una de las generaciones y proyectos estéticos en pugna representaban el conflicto, al mismo tiempo que pretendían validar sus resortes estéticos frente a los del otro.

Por un lado, Osvaldo Soriano, quien en $A$ sus plantas rendido un león utilizaba una técnica de representación habitual en su narrativa: la construcción de una alegoría para presentar los conflictos globales (de un mundo globalizado y en etapa de neocolonialismo) a nivel micro, en este caso en un pequeño e imaginario país africano llamado Bongwutsi. Desde allí, Faustino Bertoldi, un falso cónsul argentino que lleva mucho tiempo imposibilitado para comunicarse con la cancillería argentina, sigue las alternancias de la guerra de Malvinas e inicia él mismo una cruzada en contra de la representación diplomática de Gran Bretaña ${ }^{6}$.

A partir de ese momento, el conflicto en Malvinas se convierte en un asunto en torno del cual giran otros personajes, entre los que podemos destacar especialmente a Lauri, un argentino exiliado por la dictadura que en Zurich conoce a Quomo, quien se presenta como un revolucionario de Bongwutsi que planea derrocar al Emperador con un ejército de gorilas. Lauri decide ayudar al revolucionario africano solamente para aumentar las posibilidades de que Argentina (o, lo que es igual, de que el gobierno militar argentino) gane la Guerra en el Atlántico Sur, al obligar al enemigo a un doble esfuerzo bélico. Es decir que, en definitiva, el exiliado acaba siendo funcional a los intereses del ilegítimo gobierno que, también ilegítimamente, lo obligó al desarraigo ${ }^{7}$ Otro personaje estereotipado es el irlandés Theodore O’connell, un supuesto militante del IRA siempre dispuesto a colaborar en cualquier acción que pretenda desestabilizar al gobierno británico. En el transcurso de la novela, con la confluencia de todos estos seres, Bongwutsi termina por encarnar literalmente la metáfora de ser el patio del mundo y, en una especie de comedia de enredos al estilo de las películas cómicas que Soriano homenajeara en Tris-

\footnotetext{
5 "La cuestión de la guerra (literaria) y Malvinas: la disputa entre Soriano y Feiling", ponencia leída en el XIII seminario Argentino Chileno y VI seminario Cono Sur de Ciencias Sociales, Humanidades y Relaciones Internacionales "Independencias y Dictaduras del Cono Sur". Mendoza, marzo de 2016.

${ }^{6}$ Nótese cómo el enfoque de Soriano, coincide en varios puntos con la perspectiva postcolonialista que, como hemos afirmado en una nota anterior, defienden muchos de los estudios sobre del tema.

${ }^{7}$ Se trata de la misma posición frente al conflicto que intenta desmontar León Rozitchener en el ensayo mencionado en una nota anterior.
} 
te, solitario $y$ final ${ }^{8}$, se enfrentan las organizadas fuerzas de su Majestad y sus poderosos aliados internacionales con el improvisado representante argentino y su banda de perdedores. Si bien Soriano apunta a evidenciar las contradicciones de la sociedad argentina frente al hecho masivo y traumático de la guerra, sus indagaciones en ese sentido atraen menos la atención que los "gags" de los personajes.

Podría decirse que la guerra en sí misma permanece en un segundo plano mientras que los esfuerzos de Soriano intentan, aparentemente, resaltar las contradicciones de la Historia argentina mediante el seguimiento de sujetos anodinos que sufren las consecuencias de sus vaivenes (fundamentalmente en el caso de Lauri). También es evidente que el narrador intenta reflexionar sobre la equívoca constitución de nuestro "Ser Nacional" a través de una serie de símbolos muy estereotipados, que aparecen sistemáticamente en la novela y de otros rasgos arquetípicamente atribuidos a la argentinidad (de los cuales Soriano echa mano habitualmente en su narrativa). Para dar un ejemplo, solamente, podemos recordar el pasaje en que uno de los soldados imperiales de Bongwutsi, señalando un retrato de Carlos Gardel, lo llama "presidente" (I8).

El contraste entre Soriano y los escritores de la generación posterior, permite analizar la transformación de una dinámica que el campo cultural ha superpuesto a lo largo de más de un siglo, es decir, que excede en mucho al hecho de la guerra en sí. En Soriano es posible observar una característica que resulta interesante en torno a las ideas de lo que el Ser Nacional Argentino en general y la guerra en particular despiertan y que veremos repetirse en otros autores del corpus estudiado. La guerra impone una tensión ideológica: el exiliado Lauri, que es una víctima de la dictadura aunque no se reconozca a sí mismo como un militante político (sino que ha sido exiliado de un modo que no responde a la lógica del enemigo interno), se siente impresionado por la guerra y decide, por sentimiento patriótico, ayudar al gobierno que lo ha expulsado. Detrás de ese impulso parece residir la idea de que antes que nada hay que ser fiel a la patria que, a menos que sea leída en clave irónica, se trata de una elaboración confusa y superficial (y no puede descartarse la posibilidad de la clave irónica, especialmente si se recuerda que el mismo Soriano fue obligado a exiliarse durante la dictadura).

Asoma, además, un motivo en el tratamiento del tema que veremos aparecer en la literatura posterior, nos referimos a la figura del impostor. Bertoldi es un falso cónsul que usurpa un cargo que no le pertenece: nunca ha sido designado en dicha función, aunque para el resto de los dignatarios oficiales se trata del representante oficial del país. En un plano simbólico, el proceder de Bertoldi es peligrosamente equivalente al de los militares genocidas que usurparon el poder político en el país y que se atribuyeron el derecho de iniciar lo que ellos consideraron una gesta épica. Si bien Bertoldi es un representante del degradado poder civil y, fundamentalmente, un estereotipado ciudadano de a pie; el

\footnotetext{
${ }^{8}$ Hemos tratado algunos aspectos de la relación entre la narrativa de Soriano y el cine en el artículo "De buen periodista a escritor polémico. La poética de Osvaldo Soriano". En: V. G. Zonana (Ed.). Poéticas de autor en la literatura argentina (desde 1950). Volumen II. Buenos Aires: Corregidor, 2OIO, 227-27O.
} 
hecho de que la trama ficcional aborde con cierta superficialidad el asunto, sobre todo a patir de los enredos cómicos que la dominan, supone la inconsciencia de una cierta simetría entre su acción y la de la junta militar (aspecto reforzado por el ya descripto apoyo de Lauri a la causa de los militares que lo habían obligado a exiliarse) ${ }^{9}$.

Por el otro lado, y retomando nuestro artículo ya mencionado, Carlos E. Feiling se colocó explícitamente a sí mismo en las antípodas del campo literario, oponiendo al "populismo" de Soriano una concepción totalmente diferente sobre la escritura y sobre la función social del arte. Nuestra hipótesis es que esto se evidencia tanto en su producción ensayística, por ejemplo en el artículo "El culto a San Cayetano" despiadadamente a Soriano y que provocó una gran controversia; como en su vertiente ficcional, es decir, en las tres novelas que publicó a lo largo de su vida" ${ }^{\text {, }}$ en las cuales sería imposible encontrar una estrategia de representación similar a la descripta para $A$ sus plantas rendido un león. Independientemente de los enfrentamientos ideológicos desde los cuales podría analizarse la distancia que media entre un autor y el otro, es en el campo de la ficción en el cual nos pareció apropiado oponer la forma de representación sobre la guerra que se lee en las obras de ambos. Por lo tanto, en el trabajo previo del que venimos hablando, tomábamos como contrapunto de la novela de Soriano a El agua electrizada, la primera novela de Feiling, en la cual se veían reflejadas muchas de las ideas desarrolladas en su veta ensayística.

Allí, y de acuerdo a las características que Drucaroff (2OII) propone para las generaciones de la postdictadura, Feiling se detenía en los eventos de la guerra pero su objetivo fundamental era desnudar las secuelas del período 1976-I982, el trauma, podríamos decir, que la dictadura y la guerra habían producido en la sociedad argentina y que ésta se negaba a admitir. Un elemento que corrobora esta lectura es el hecho de que, a diferencia de la obra de Soriano, aquí la acción narrada transcurre años después de terminado el conflicto bélico, ya con la democracia instalada. Tony, el protagonista, es un ex-liceísta

\footnotetext{
9 En "Trashumantes de neblina, no las hemos de encontrar", Kohan, Blanco e Imperatore proponen otra lectura de la novela, en la que estas características estarían funcionando como una especie de fuerza cuestionadora del discurso oficial.

Io Es en este artículo donde Feiling tilda a la literatura de Soriano como "populista" y lo fustiga a partir del trazado de un paralelismo entre su literatura y la acción política de Carlos Menem. En esa dirección, van algunas de las frases más célebres del ensayo. Sirvan de ejemplo del tono general, los siguientes fragmentos, que también explican por qué Soriano se molestó tanto con Feiling: "Una sombra ya pronto serás, la quinta y exitosa novela de Osvaldo Soriano, le hace a la literatura argentina lo mismo que el Excelentísimo Sr. Presidente al país" (43) y "Una sombra... resulta una larguísima falacia, la forma literaria del argumentun ad populum tan cultivado por el Excelentísimo Sr. Presidente en sus discursos y apariciones públicas" (44). El ensayo fue publicado en la revista Babel en I99I y recogido luego en Con toda intención (las citas en este trabajo corresponden a este volumen). Babel. Revista de libros salió entre abril de I988 y marzo de I991 y nucleó a los escritores “experimentalistas" de la nueva camada. En cierto sentido fue el órgano de difusión del grupo Shanghai. Sobre este punto, ver el libro de Drucaroff (especialmente pp.57-67), el ensayo de Hernán Sassi y las referencias a la generación realizadas por Kurlat Ares (pp.97 y ss.).

II C.E. Feiling murió de leucemia en julio de i997, cuando tenía 36 años. Había publicado un libro de poemas, titulado Amor a Roma, y tres novelas: El agua electrizada (I992), Un poeta nacional (I993) y El mal menor (I996). Las citas de El agua electrizada provienen del volumen Los cuatro elementos (2007) que reúne toda la producción novelística de Feiling.
} 
cuyo mejor amigo, Juan Carlos "el indio", aparece muerto en una confusa escena de suicidio $^{\mathrm{I} 2}$. Las sospechas de Tony dan lugar al desarrollo de una trama policial que va develando, como decíamos, la subsistencia de las redes de corrupción establecidas por los militares en el período de la dictadura. Obviamente la guerra no puede entenderse fuera de la acción exterminadora del gobierno militar y para ello es preciso, además, desprenderla del efecto sentimental y de empatía que genera en la sociedad, algo que claramente Soriano no intentó hacer. Un ejemplo del asunto se puede leer en el pasaje que copiamos a continuación y que tiene lugar durante el entierro de su amigo, donde Tony se encuentra con sus ex-camaradas y escucha a uno de ellos recordar los días de la guerra:

Tony dejó de llorar. Fue el momento justo, porque el imbécil del Turco ya arrancaba con la Guerra de Malvinas. The Fucklands (...). Juan Carlos, en Goose Green, había sido la única razón por la que él hubiera lamentado que los ingleses mataran más militares argentinos. Aunque era cierto que la clase media se lo merecía, como se merecía todas las lacras: los militares, el Peronismo, la Iglesia Católica (Feiling: 2007, 27, las cursivas son nuestras).

Por una parte, la novela de Feiling resalta cruelmente la hipocresía de la sociedad que ha avalado el conflicto bélico a partir del discurso triunfalista instalado por los militares. En este sentido, el desarrollo de la trama intenta de modo muy claro establecer una correlación entre la política, la dictadura, la guerra y la decadencia social de la Argentina de los años noventa. Por otra parte, y en una dimensión más polémica, los supuestos héroes de Malvinas son desenmascarados, ya que no se trata de los conscriptos rasos que habían sido obligados a pelear y a morir en las islas, sino de los mismos canallas con los cuales había compartido sus años de Liceo: claramente el narrador habla de "militares argentinos" y no de soldados.

Como se aprecia, no hay manera de superponer, al sombrío plan de los dictadores, una justificación acerca de la nobleza de la causa Malvinas. La guerra es para Feiling solamente una atrocidad más perpetrada por los militares para ocultar las otras atrocidades que estaban cometiendo. En una posición diametralmente opuesta a la exhibida por Soriano, no hay ningún resquicio posible por donde la situación pudiera despertar simpatía. En la novela de Feiling la simulación no está en el mismo nivel que en la de Soriano. En El agua electrizada no solamente la guerra es un evento del pasado que debe revisarse y sobre el cual los argentinos deben hacer un mea culpa, sino que las estructuras

\footnotetext{
I2 La novela está plagada de referencias autobiográficas. En un postfacio incluido en Los cuatro elementos (volumen que reúne las tres novelas editadas por Feiling más un capítulo de una cuarta en la que trabajaba al momento de su muerte), Gabriela Esquivada señala algunas de esas referencias: la primera es que el nombre del protagonista coincide con el de un tío bisabuelo del escritor que también se había dedicado a la literatura y que había publicado dos libros bastante conocidos. La segunda es que Feiling, al igual que el protagonista de El agua electrizada, asistió al Liceo Naval a partir de I975 y alli presenció algunos de los efectos de la represión estatal perpetrada por los militares. Por último, otro dato autorreferencial en la novela es, justamente, el suicidio de un querido amigo de la época del Liceo: José Luis Ruiz, quien se quitó la vida en I988, es decir, apenas un año antes de que Juan Carlos se suicide en la ficción.
} 
que fundaron e instalaron quienes condujeron al país a la guerra, siguen activas y podrían estar ocasionando muertes todavía en el presente. Allí es donde reside la farsa: en dar por acabado lo que, para terror de muchos y merced a la ignorancia de otros tantos, todavía goza de buena salud.

\section{Un marco en la historia literaria: exagerar las diferencias}

Está claro que la perspectiva generacional/ideológica es una fuente de análisis vasta y rica, tal como lo demuestra el ya citado trabajo de Elsa Drucaroff cuyas ideas rectoras, como se dijo antes, hemos seguido en nuestro propio ensayo sobre la disputa Soriano-Feiling. Drucaroff ha insistido en la necesidad de matizar las diferencias generacionales, sobre todo cuando son explotadas por los mismos escritores, ya que a veces apuntan a operaciones de legitimación que no necesariamente tienen un correlato en la producción estética ${ }^{13}$. Según la misma estudiosa, en referencia a las dos generaciones representadas en la polémica que hemos comentado más arriba, es posible verificar que no todos los autores "realistas" son atacados desde las páginas de Babel, por lo menos no con la intensidad con la que Feiling se ocupa de Soriano en "El culto a San Cayetano". Hay cierta heterogeneidad en el grupo y también en la línea editorial de la revista ya que, por ejemplo, no atacaron a escritores realistas y narrativistas asesinados por la dictadura como Haroldo Conti o Rodolfo Walsh, y lo mismo sucede con escritores extranjeros que están vivos y que Babel presenta para el público argentino. Toda esa ambivalencia, lleva a Drucaroff a asegurar que: "a la hora de la verdad, los únicos escritores realistas enemigos de Babel son los argentinos que están vivos y que ocupan las vidrieras de las librerías o las columnas en los suplementos, los lugares que los jóvenes babélicos quisieran ocupar" (2OII: 67).

Las disidencias intrageneracionales, siguiendo a la misma autora, son representadas habitualmente por la distancia entre la línea editorial que sigue la revista Babel, con un concepto más refinado y elitista sobre la literatura, y la línea que sigue la colección Biblioteca del sur, dirigida por Juan Forn y volcada hacia una concepción más popular del arte literario. Esta oposición puertas adentro de la generación, debe ser deconstruida también, puesto que tal y como lo señala Drucaroff: "El propio Feiling (...) es una prueba de lo inauténtico del supuesto enfrentamiento: su magnífica prosa es ágil y afín con los géneros masivos de la industria cultural" (20II: 85).

Esta impresión se refuerza si atendemos a las explicaciones de Silvia Kurlat Ares, cuando señala que los enfrentamientos ideológicos-generacionales no se encausan, sin embargo, a través de una respuesta estéticamente orgánica:

I3 Para un ejemplo sobre este asunto en particular, también pueden verse el artículo de Hernán Sassi y el libro de Silvia Kurlat Ares que hemos mencionado en una nota anterior. 
Para los años ochenta la intelectualidad argentina se debatía en sus propias vacilaciones, en una situación pública donde ya no era posible esgrimir ni el mismo discurso ni las mismas posturas que en la década precedente. Podría decirse que ninguno de los sectores que hasta ese momento habían sido hegemónicos en el campo cultural logra sintetizar algún tipo de propuesta para los años de la democracia. En ese vacío se instala una vanguardia que se lee a sí misma como cínica y contestataria y que, sin embargo, caerá en la misma trampa del deseo del estado que sus antecesores. Esos jóvenes operan una síntesis de los fracasos de la izquierda y el liberalismo bajo el rótulo de la posmodernidad (2006: I77)

Podría decirse, sin demasiada pretensión de originalidad, que las posturas sostenidas por los escritores son exageradas adrede, son construidas para reforzar su performance en el campo literario ${ }^{\mathrm{I} 4}$. Esas diferencias tienen un correlato estético, pero muchas veces no logran ser todo lo representativas y lo definitorias respecto del diferencial entre generaciones o grupos que sus autores pretenden y, en esto, coinciden tanto Drucaroff como Kurlat Ares. Juan Forn no expresa la misma posición estética ni ideológica que Feiling, aunque sus resultados concretos, en ciertos sentidos, tienden a acercarse.

\section{El (manual del) delito como marco de análisis: el asesinato ritual de los hijos}

Como hemos dejado entrever, Malvinas es un tema polémico que sirve, en sus múltiples lecturas, para distanciar (o, por el contrario, para acercar) estéticas que se lanzan en la posguerra. Es, paradójicamente, un campo de batalla simbólico que se superpone al trágico campo de batalla real. La batalla simbólica, como siempre, gira en torno a qué sí y a qué no puede decirse (y a cómo debe decirse), acerca de la Guerra de Malvinas. Es una marca fuerte, sangrante, que cruza la época, una batalla discursiva. Pero no es nuestro objetivo analizar los discursos sobre Malvinas ni inventariar las obras que se ocupan del tema. Nos proponemos una tarea más específica y más modesta que, por cierto, ya ha sido sugerida en las páginas precedentes: la de detectar un leit motiv relacionado con la falsedad y la simulación en producciones de los escritores que han tratado el tema.

Este interés, surge de una primera idea: la de que la guerra de $\mathrm{r}_{92}$ fue, en definitiva, un acto perpetuado por la dictadura y apoyado masiva y pasivamente por gran parte de la sociedad argentina . Es una mancha en la conciencia cuyo significado debió ser reelaborado y que va del triunfalismo a la denuncia del criminal acto cometido contra

\footnotetext{
${ }^{\text {I4 }}$ Aunque sea una idea formulada con otro sentido, seguimos en esta línea a María Teresa Gramuglio cuando, analizando textos metaficcionales, asegura: "más allá de las constantes retóricas, que a veces parecieran vaciarlas de su especificidad semántica, las figuras de escritor remiten inexorablemente, por un lado, a la constitución de una subjetividad fechada, y por el otro, al estado del campo literario a que pertenece el escritor, a los conflictos presentes en ese campo, a las formas de acceso posible y al conjunto de condiciones cambiantes que regulan la practica literaria"(39). Es decir que en el caso que nos ocupa, la inmediatez de los conflictos genera rupturas estridentes que, sin embargo, no siempre son visibles años más tarde. Las diferencias y distancias inter e intrageneracionales, en el campo literario de la primera posdictadura, se han achicado notablemente dos décadas más tarde.

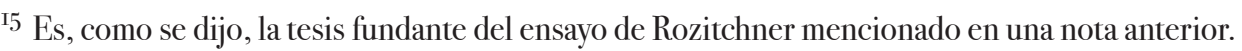


los jóvenes, que fueron obligados a pelear en condiciones perversas. Se trata de un largo camino que, de hecho, aún seguimos recorriendo. Lo cierto es que se pasó, en un breve lapso, del apoyo masivo en la Plaza de Mayo al silencio culpable de la sociedad que ocultó, encerró e hizo callar a los que volvían. En ese escenario las obras literarias que han abordado el tema, lo han hecho a menudo desde la mirada del delito, es decir, la guerra como delito. Y, concibiendo el delito como un punto de partida para el análisis, nos gustaría inscribirlo como una continuidad en El cuerpo (muy amplio, como lo ha demostrado Ludmer) del delito (1999): se trata del delito de los militares, de la guerra como un delito más de lesa humanidad, pero también de pequeños delitos en torno de ese gran delito o, si se quiere, del Delito englobante que fue la dictadura y, en definitiva, la guerra como acto de la dictadura. El delito como tensión y, por lo tanto, como instrumento crítico no es nuevo, tal y como presenta su manual Ludmer:

Como bien lo sabían Marx y Freud, [el delito] es un instrumento crítico ideal porque es histórico, cultural, político, económico, jurídico, social y literario a la vez: es una de esas nociones articuladoras que están en o entre todos los campos (I999: I4).

Pero no se trata aquí de establecer esos límites, sino de analizar cómo ese elemento delictivo se cuela en las obras literarias sobre la guerra, en los "cuentos sobre la guerra", para utilizar la terminología del Cuerpo del delito. Si como Ludmer, siguiendo a Freud, entendemos que "la conciencia de culpabilidad nace en el acto criminal" (I3), podemos discutir el hecho de que esa conciencia surge en el hijo que asesina al padre e invertir los términos: la conciencia culpable surge, en este caso, en el sacrificio ritual del padre filicida. Lo que funda el nuevo periodo democrático es el sacrificio de los miles de jóvenes muertos a manos de la dictadura y, entre ellos, los conscriptos que fueron enviados al Atlántico Sur. Dice Ludmer:

Fundar una cultura a partir del "delito" del menor, de la segunda generación, o fundarla en el "delito" del segundo sexo, implicaría no sólo excluir la anticultura, sino postular una subjetividad segunda culpable. Y también un pacto. Así parecen funcionar, muy a primera vista, las ficciones de identidad cultural con delito (1999: I3, cursiva en el original).

Como decíamos, en el caso de Malvinas y de la dictadura, no se trata de la muerte del padre a manos de la horda, es decir, del crimen ritual de los hijos que luego de matarlo se comen el cuerpo del padre, como propone Freud; se trata, por el contrario, del crimen paterno, del sacrificio, no abortado a tiempo, de Isaac sobre la piedra a manos de Abraham. De esta especie de pecado, surge la línea que piensa la guerra como un crimen de la sociedad, línea en la cual se posiciona Feiling en la ficción, con reflexiones del tipo de las que hemos copiado más arriba ${ }^{\mathrm{I}}$; pero que él ya experimentaba antes, en su propia vida, por ejemplo, al chocar con el escepticismo de sus padres cuando el joven cadete les contó

\footnotetext{
${ }^{\text {I6 }}$ Ver el apartado “Antecedentes...”, especialmente las citas que contienen las reflexiones de Hope durante el entierro de su amigo.
} 
lo que veía en el internador ${ }^{\mathrm{r}}$.

Sin embargo, la guerra también enmarca otros delitos, delitos menores (y no necesariamente contra los menores), como los delitos de usurpación de la identidad.

\section{El gran campo de la simulación y el triángulo que se cierra}

$\mathrm{Si}$, como se dijo en un apartado previo, es una ilusión imaginar una generación homogénea, una acción posible y deseable es la de trazar líneas de continuidad inter e intrageneracionales. Una de esas líneas, podría ser el delito ya que, tal y como lo señala Ludmer, "sirve para trazar límites, diferenciar y excluir. Con el delito se construyen conciencias culpables y fábulas de fundación y de identidad cultural” (I999: ı4). Y dentro de las ficciones del delito, una de las modalidades que la autora desarrolla es la de los simuladores ${ }^{18}$.

Ludmer piensa la simulación, en principio, como una transgresión de los advenedizos frente a la norma impuesta desde el Estado Liberal. El problema, dice la autora, que rige a esta literatura naturalista "es la relación entre dos campos de determinaciones, el biológico-genético y el social. ¿Dónde articular la dualidad? Y además ¿cómo ligar el saber científico y la decisión ética y jurídica?” (79). Una de las posibilidades que se presentan es la del simulador de talento, cuyo ejemplo paradigmático es el personaje de Genaro que aparece en la novela En la sangre (I887) de Eugenio Cambaceres. Según Ludmer, el delito de la simulación es especialmente fructífero en un momento en que el estado liberal se redefine para encarar una nueva etapa: es, justamente, ese potencial el que la autora observa en los simuladores de talento que falsifican sus exámenes de física en el Colegio Nacional. El simulador de talento retratado por Cambaceres es, en definitiva, un sujeto que se cuela hacia un mundo que originalmente le está vedado.

A finales del siglo XX encontramos que, en el nuevo estado que se redefine después de la dictadura (dictadura que se imaginaba a sí misma como liberal), aparece el simulador de veteranía, el sujeto que se presenta como excombatiente y que también pretende colarse, aunque esta vez como objeto del discurso sobre Malvinas en su versión del lamento $^{19}$.

\footnotetext{
I7 Según Gabriela Esquivada, en el Postfacio de Los cuatro elementos ya citado, Feiling: "Un día dijo a su madre: 'Hay cadáveres (...). Se los ve en el río'. Ella y Geoffrey [su padre] no le creyeron. Años después debieron hacerlo" (5OI).

I8 María Elena Molina en su artículo "Guerra de Malvinas: la literatura argentina y el desafío de la autocrítica" introduce también el problema de la simulación y lo utiliza como elemento de lectura de Las Islas de Gamerro y de "Memorándum Almazán” de Forn. Sin embargo, el marco teórico y los objetivos perseguidos difieren de los que proponemos aquí.

${ }^{19}$ La versión triunfalista y la versión del lamento son, según lo proponen Kohan, Blanco e Imperatore en su artículo "Trashumantes de neblina, no las hemos de encontrar", Tas dos maneras de contar la guerra que han predominado en la disputa por la memoria colectiva. En el mismo texto, además, aseguran que aunque la segunda versión se presente como antagónica de la triunfalista, en realidad no la cuestiona en sus fundamentos y ambas terminan inscribiéndose en la misma lógica del Gran Relato Argentino (82-3). Si nos posicionamos en el campo de los simuladores de la Guerra podría decirse que, antes de los simuladores de veteranía de los que estamos por ocuparnos y que representan una crítica deconstructiva de la versión del lamento, existen los simuladores de triunfos que pretenden encarnar y criticar la versión triunfalista, aunque el objetivo no sea siempre bien alcanzado. Los casos paradigmáticos en nuestro corpus, como dijimos antes, son el del falso cónsul que festeja la declaración de la Guerra, Faustino Bertoldi, y el del exiliado Lauri, que decide beneficiar a quienes lo expulsaron del país, en la novela de Osvaldo Soriano.
} 
Probablemente, una de las más críticas miradas al respecto pueda leerse en "Memorándum Almazán”, un cuento de Juan Forn incluido en Nadar de noche (I99I). Este texto narra la historia de un joven, Matías Almazán, que se presenta en la embajada argentina en Chile aduciendo ser excombatiente. En su versión original la historia transcurre, aparentemente, entre el final del invierno y la primavera de I982 o I983, ya que el chico ${ }^{20}$ tiene todavía dieciocho años ${ }^{21}$. Asegura sufrir estrés postraumático, motivo por el cual ha perdido el habla y, por lo tanto, se comunica con los demás a través de mensajes que va escribiendo en un anotador que lleva consigo. Lo primero que hace, antes de ser atendido, es justamente dar a conocer su pasado en las Islas:

\author{
SOY ARGENTINO \\ EX COMBATIENTE EN LAS ISLAS \\ QUIERO VER AL EMBAJADOR (I996: 78)
}

Más adelante, cuando logra llegar hasta el escritorio de una de las secretarias que trabajan allí, agrega la información sobre el trauma:

\author{
¿ME VA A RECIBIR EL EMBAJADOR? \\ OIGO PERFECTAMENTE \\ LO QUE NO PUEDO ES HABLAR (1996: 82)
}

Coincidimos con Drucaroff cuando afirma que el "chico" explota la culpa colectiva de los frívolos diplomáticos argentinos apostados en Santiago, especialmente la de Aranguren $^{22}$, para mejorar su posición social (Los prisioneros..., 2OII: II2). Rememo-

\footnotetext{
${ }^{20}$ Es muy importante que Forn haya elegido aludir al personaje siempre con la palabra "chico" desde el comienzo: "En algún momento de esas dos semanas apareció el chico por primera vez" (78), "el chico entré con su anotador y su lápiz en la mano" (82), "el chico, parece, esperó a que Aranguren diese el primer paso" (85), entre otros ejemplos. El término empleado por el narrador apunta, inevitablemente, a la tradición inaugurada por Daniel Kon en Los chicos de la guerra, apenas terminada la contienda bélica (I982). Opera, en este sentido, la versión del lamento ya mencionada. Según los autores de "Trashumantes de neblina, no las hemos de encontrar" esta estrategia aplicada desde la narrativa testimonial tiende más a presentar a los "chicos" como víctimas de sus propios oficiales que de los ingleses, aunque no cambia el trasfondo de la argumentación nacionalista: la causa de Malvinas fue justa aunque estuvo mal dirigida. Sin embargo, según Graciela Mantiñan, este enfoque les impide, a dichos estudiosos, ver los "rasgos de afirmación identitaria que niegan la visión convencional de heroísmo propuesta por el sujeto textual” (9) que es visible en algunos de los testimonios recogidos por Kon. En todo caso, esta formalización del sujeto como un "chico", coincide con la idea de la "culpa" que determina las acciones de Aranguren (el funcionario que decide apadrinarlo en el cuento) y que, en definitiva, causarán su perdición en la carrera diplomática.

${ }^{2 \mathrm{I}}$ En ediciones posteriores del libro, entre otras modificaciones más o menos importantes, Forn ha introducido un sutil cambio en este punto y ha hecho al personaje un año mavor, lo cual, evidentemente, apunta a darle mavor credibilidad al relato. De sostener la versión original la cuenta daría que Almazán habría sido conscripto, posiblemente, con I7 años o, en caso contrario, serían muy apretados los tiempos para una serie de sucesos mencionados y que debían tener lugar después del I4 de junio de i982. Por ejemplo, en el informe de inteligencia que solicita el narrador a Buenos Aires se menciona, como una particularidad, que Almazán no tuviera contacto con asociaciones de excombatientes, lo cual sería difícil de postular como un rasgo distintivo a tan pocos meses de finalizadas las acciones bélicas.

${ }^{22}$ El narrador lo presenta de este modo: "Para que se entienda esto hay que describir a Aranguren. Como muchos en el servicio diplomático, como muchos arribistas en general, Aranguren tenía una estampa casi perfecta: alto, ancho de hombros, facciones mediterráneas y una sonrisa más bien infrecuente pero bastante irresistible cuando necesitaba apelar a ella" (83). Inmediatamente explica que habla en pasado porque después de lo sucedido comenzó a padecer diferentes tics que le deformaban la expresion, "detalles ínfimos pero decisivos en un tipo que usaba su apariencia como tarjeta de presentación" (83).
} 
rando los sucesos, ya caído en desgracia, Aranguren confirma estas impresiones cuando justifica su proceder:

Tenés que entenderlo tal como lo sentí yo en ese momento (...): el chico había perdido el habla para ser un héroe de guerra. Ya sé que suena raro, pero parecía realmente una elección, no una trágica circunstancia. Y con sólo mirarlo sentías que él lo tenía muy claro (ı996: 86, cursiva en el original).

De modo que la culpa y el nacionalismo son los encargados de tocar alguna fibra interna, logrando la entrada en el bien resguardado mundo de los diplomáticos ${ }^{23}$. Aunque el principal castigo terminara, una vez descubierta la tramoya, recayendo sobre Aranguren, está claro que todos en la embajada (a excepción del narrador) han sido presa de sentimientos similares. Esto queda en evidencia cuando Aranguren recibe a Almazán en su despacho y el chico le solicita un crédito para comprar ropa. A cambio del dinero, como garantía, Almazán quiere dejar su "bruto puñal del Ejército Argentino” que llevó consigo todo el tiempo, desde que solicitó entrar al edificio hasta que estuvo a solas con Aranguren:

Nadie lo había revisado, así de simple y estúpidamente extraordinario: bastaba que apareciese un vago que decía ser mudo y ex combatiente de Malvinas para que todo el andamiaje de seguridad de la embajada se atascase en nombre de una compasión mal entendida (1996: 87).

La simulación de veteranía abre las puertas del mundo prohibido de la embajada. El muchacho, rápidamente, asciende: consigue buena ropa, trabajo, amigos influyentes, participa de galas, es admirado por casi todos y también comienza una relación amorosa con una de las secretarias de la embajada que, además, lo acoge en su casa. Almazán se cuela.

Finalmente, el engaño es descubierto por casualidad: un accidente casero revela que el chico no es mudo, ni excombatiente, ni siquiera es argentino. Tal circunstancia, obviamente, marca su expulsión del mundo de la embajada y marca, también, el final de la simulación de veteranía. Pero, además, desnuda la línea que construye un triángulo entre Soriano, Feiling y Forn: éste representa una tercera variante, aquella que une las dos generaciones. Porque lo que surge, nuevamente, es la representación de la guerra como un efecto de hipocresía. El mismo nacionalismo irreflexivo (en reemplazo de la razón lúcida) que alentaba a los personajes de Soriano a actuar a favor del gobierno que los expulsaba o que los olvidaba en el remoto patio del mundo, es el que en Forn propicia

\footnotetext{
${ }^{23}$ El narrador presenta ese mundo del siguiente modo: "Hay algo en la naturaleza de todo diplomático que nos hace temer las situaciones imprevistas. Nuestro trabajo, nuestra vida misma, se rigen por un férreo código protocolar que nos evita toda sorpresa incómoda. Y con sorpresa quiero abarcar todo aquello que nos involucra y compromete, sin que nos demos cuenta y de una manera no protocolar, en asuntos que nos llevan a actuar guiados por intuiciones de consecuencias incontrolables, que nos meterían por un instante en esa vida que late desordenada y espasmódica fuera del micromundo diplomático" (8I-82).
} 
la caída del prominente funcionario diplomático y es el mismo, por supuesto, que movió a quienes vivaron a Galtieri en la Plaza de Mayo (y que es lo que denuncia el narrador de Feiling cuando asegura que la clase media argentina merece todos sus males). Un detalle muy importante, que no debería pasarse por alto, es que el chico originalmente intentó su simulación de veteranía en Argentina:

estaba ilegal en Mendoza y creyó que, trucando esos documentos [los del verdadero Almazán] con su foto, le sería más fácil conseguir trabajo. No tuvo en cuenta que nadie toma así como asía un ex Malvinas. Entonces volvió a Chile (Forn, 1996: IO4, las cursivas son nuestras).

Las preguntas obvias son ¿por qué nadie da trabajo a un excombatiente? ¿Podría plantearse el interrogante de que el sentimiento nacionalista que despierta la causa Malvinas es solamente discursivo pero no práctico? ¿Podría pensarse que esa diferencia entre el sentimiento (manifestado discursivamente en las variables del triunfalismo y del lamento) y la práctica es un acto de hipocresía que solamente sirve para ocultar la vergüenza colectiva de haber acompañado con entusiasmo una guerra? O, lo que es lo mismo, ¿tiene otro valor ser excombatiente fuera que dentro de la Argentina ${ }^{24}$ ? Los excombatientes no volvieron solamente lastimados y mutilados físicamente, sino psíquicamente. De hecho, según el informe de cancillería solicitado por el narrador, Almazán no ha sufrido ningún daño en el sistema foniátrico sino que "la mudez era un trastorno de origen psíquico" (9o). Y aquí es donde cierra el triángulo; no en la evidente hipocresía que señalan Forn y Feiling, sino en la locura de la que nadie quiere hacerse cargo. Porque el presunto y previsible trastorno psiquiátrico de Almazán, del verdadero, del que cedió su identidad al impostor para quedarse a vivir en la montaña, empalma con la locura que Charlie Feiling atribuye al excombatiente en El agua electrizada. Como dice Irene, la hermana de Juan Carlos: "Mi hermano estaba muy mal, muy rayado. Lo de Malvinas terminó de liquidarlo, y después vino la enfermedad" (Feiling, 2007: I36). Irene se refiere aquí a la leucemia que padeciera su hermano, enfermedad a la que se ataca como si fuera una "célula guerrillera” ( 136$)$, y, después, el suicidio (real o instigado, es decir, simulado), que es uno de los finales más recurrentes de los verdaderos excombatientes. La correlación resultante: guerra, locura, enfermedad, suicidio.

\footnotetext{
${ }^{24}$ Como se señala en "Trashumantes de neblina, no las hemos de encontrar" no es un dato despreciable el hecho de que las ficciones de Soriano y de Forn que consideramos tengan como escenario las embajadas o los consulados, que representan el espacio propio en el ajeno, y que, por lo tanto, corroe de algún modo los principios de la identidad: ¿dónde es el adentro y donde es el afuera? Si la embajada argentina es territorio argentino en Chile ¿por qué allí un excombatiente tiene el reconocimiento que se le niega en Mendoza?
} 


\section{La Segunda Guerra de Malvinas como reality show}

Si seguimos el esquema generacional propuesto por Elsa Drucaroff, cabría preguntarse de qué modo se aborda el tema en la segunda generación de postdictadura y si existe alguna continuidad con los modelos críticos de representación. Los escritores correspondientes a esta segunda camada nacieron después de la guerra o eran muy pequeños cuando tuvo lugar. En este sentido, el recuerdo de la Guerra de Malvinas encuadra para esta generación en la idea de postmemoria ${ }^{25}$ y, por lo tanto, en el campo de la simulación absoluta y en el de la pura narración.

Porque, ciertamente, la simulación no solamente es pensable en los términos de suplantación de la identidad (simulación de veteranía) que hemos estado comentando en el apartado previo. La propia Ludmer, siguiendo a Baudrillard, señala que ya no se trata ni de duplicar, ni de imitar ni de parodiar lo real, sino de "de una sustitución de lo real por los signos de lo real, es decir, de una operación de disuación de todo proceso real por su doble operatorio" (Ludmer, r999: ı29). Para la segunda generación de postdictadura, recordar la guerra es recurrir a una narración heredada sobre la guerra, a un discurso que está en el lugar de los hechos, que los construye performativamente. En otras palabras: que los simula ${ }^{26}$.

Cataratas de Hernán Vanoli, ejemplifica a la perfección estas ideas desarrolladas por Ludmer y por Drucaroff. El mundo distópico presentado en la novela incluye una referencia a la Guerra de Malvinas a través de Jorge Osinde ${ }^{27}$, quien trabaja como sicario: según consta en la base de datos de Google Iris (el sistema de información biónico que utilizan los personajes de la novela para interactuar permanentemente), Jorge Osinde "había participado en la recuperación final de las islas Malvinas y (...) había fallecido de regreso, en un accidente aéreo" (2OI5: 273). La recuperación final de las islas a la que se refiere es una puesta en escena, tipo reality show, acordada entre las compañías petroleras y el gobierno a través de "una difusión espectacular que al mismo tiempo sirviera como reparación histórica por la derrota” (273). Osinde participa del montaje como voluntario, junto a otros cuatrocientos cincuenta desempleados. No se trata solamente

\footnotetext{
25 Según Marianne Hirsch: "Postmemory characterizes the experience of those who grow up dominated by narratives that preceded their birth, whose own belated stories are evacuated by the stories of the previous generation shaped by traumatic events that can be neither understood or recreated" (Cit. por Mónica Szurmuk, "Usos de la postmemoria: Lenta biografía de Sergio Chejfec", 3І2).

${ }^{26}$ Como bien lo señala María Elena Molina, Las islas (I998) de Carlos Gamerro, también incluye elementos relacionados con la simulación, fundamentalmente en lo que respecta al videojuego que Felipe desarrolla. Esta realidad virtual, que propone la ficción del juego, podría pensarse como una etapa de simulación intermedia, en la que los jugadores (los excombatientes) logran un paliativo para las duras experiencias del pasado: fundamentalmente porque pueden ganar la Guerra a traves del juego, que ha sido programado para eso.

${ }^{27}$ Imposible pasar por alto (entre otras que se registan en la novela) la homonimia del personaje mencionado con el Coronel Jorge Manuel Osinde, sindicado como uno de los principales responsables de "La Masacre de Ezeiza" (ocurrida el $2 \mathrm{O}$ de junio de 1973 cuando Juan Domingo Perón regresó a la Argentina después de su largo exilio en España). Según señalan numerosas fuentes, crónicas de la época y testigos presenciales de los hechos, Osinde (quien era amigo personal de López Rega), tenía a su cargo la seguridad del masivo evento, pero también tenía órdenes explícitas para impedir que las columnas de las agrupaciones peronistas consideradas de "izquierda" se acercaran al escenario dominado por sus hombres. Finalmente, fue desde allí desde donde partieron los disparos que causaron heridos y víctimas fatales entre los asistentes. Tomás Eloy Martínez ha tratado ficcionalmente este hecho en La novela de Perón (1985).
} 
de imaginar una Segunda Guerra de Malvinas que opere como una "recuperación final" (terminología que remite a la Segunda Guerra Mundial y a la "solución final para el problema judío”), de manera que sirva para olvidar la derrota de I982, se trata de que este nuevo enfrentamiento es en sí mismo y literalmente una simulación. Si los sucesos de I982 fueron un intento desesperado por parte de los militares para sostenerse en el poder y, en ese sentido, ya podría hablarse de una puesta en escena; la guerra que imagina Vanoli en el futuro es un simulacro del simulacro que fue la de r982:

El experimento había empezado funcionando bien (...). En dos días la recuperación de las islas se convirtió en un caso testigo para campañas de viralización (...). La empresa Pixar se había encargado de los efectos especiales de la guerra (...). Muchos periodistas independientes se habían ocupado en desmentir la operación, pero cada vez importaba menos. Los anunciantes se desesperaban por pautar, y, más allá de los comentaristas especializados, a nadie le importaba demasiado si eso era cierto o no porque era una guerra en la cual nunca se veían cadáveres, al igual que en la transmisión de las guerras reales (2OI5: 274).

La espectacularización de la guerra busca ocultar, aunque se apele a sentimientos patrióticos de justicia y reparación (o especialmente porque se apela a ellos), que siempre hay otros intereses ocultos, fundamentalmente económicos, que manejan las decisiones. En el caso de la nueva guerra, el montaje tiene que ver tanto con las empresas petroleras como con la venta de pauta publicitaria, es decir de negocios privados. Este ocultamiento de los verdaderos móviles, se revela muy pronto como un acto criminal por parte de los responsables de la guerra y comienzan a surgir voces que alertan al respecto. Uno de los soldados, contraviniendo las normas de la "producción”, filma con una cámara la intimidad de las trincheras y de las carpas y pretende organizar al resto de sus compañeros para sabotear la farsa: "Jorge Osinde había leído sobre la cantidad de suicidios con posteridad a la guerra de I982. El traidor intentaba lograr eso. Volverlos locos" (275, las cursivas son nuestras). Lentamente, la guerra falsa se revela tan verdadera como la original, o viceversa. El soldado rebelde, que se llama Rodolfo, los insta a entregar las armas y a contactar a la prensa internacional antes de que sea demasiado tarde porque, según él, planean borrarles la memoria a todos los falsos soldados para que no puedan contar lo que han visto:

[Rodolfo] Decía que terminarían en diferentes hospicios psiquiátricos, como verdaderos combatientes, porque todo el mundo quería disfrutar de la ambigüedad acerca de si esa guerra había tenido lugar o no: la sociedad necesitaba esa imagen de los excombatientes (20I5: 276).

Estamos, nuevamente, en el campo de la simulación, aunque hemos pasado de una ficción con simuladores a una ficción con simulación, de un delito individual a un delito colectivo, de una simulación a partir del hecho a una simulación de los hechos. La guerra simulada se convierte en una máquina que debe generar, para poder existir, excombatientes locos (aunque estos no simulados, sino reales) a los que se pueda compadecer mientras hipócritamente se les niega trabajo, como sucedía también en "Memorándum 
Almazán”. Sin embargo Osinde, a diferencia del muchacho chileno que se hace pasar por Almazán, no quiere ser un falso excombatiente. Su conflicto, justamente, reside en la falsedad original de la situación: lo que quiere es pasar de actor de soldado a ser un verdadero soldado y, con este objetivo, se ofrece a los técnicos de producción para causar una masacre real ${ }^{28}$ :

Los técnicos dudaron. Tenían dos Itacas, pero por seguridad, para proteger los equipos. Sabían que la filmación de un soldado loco y asesino era un negocio redondo (...). Consideraron la situación. Consideraron que la escoria que les había hecho el encargo eran políticos. Las muertes reales iban a traer una explosión de raiting y los políticos eran vampiros adictos al raiting. Podían decir que se les había ido de las manos (2015: 277, cursivas nuestras).

Osinde comienza la matanza eliminando a Rodolfo y a Alcaraz, otro compañero, aunque luego recibe un golpe en la cabeza y despierta internado en un hospital, de donde después de simular inconsciencia y senilidad (279), logra escapar. En otras palabras, el sistema logra lo que necesitaba: un soldado loco que se dedicará a realizar tareas de sicario para diferentes jefes, incluyendo a la policía. Osinde es poco confiable y, de hecho, sufre trastornos psiquiátricos que le permiten asesinar a sangre fría, al mismo tiempo que desea parecerse a Donald Trump (28I). En cuanto a Malvinas, fundamentalmente, nunca queda claro si la guerra y la masacre realmente acontecieron o no:

Jorge Osinde debió aceptar que no recordaba casi nada de su situación anterior al hospital (...).

De vez en cuando Jorge Osinde soñaba con Alcaraz y con Rodolfo. En su sueño los reclutas eran dos enfermeros que le clavaban inyecciones en los ojos. Después sobrevenían sonidos de disparos que podían dejarlo en cama, al borde del delirio, durante semanas (2015: 28I).

La Segunda Guerra de Malvinas queda así teñida con la sospecha de la locura del actor-veterano. No es posible asegurar fehacientemente, ni siquiera, si la farsa tuvo o no lugar. En los foros de Google Iris sigue discutiéndose si la guerra aconteció y todo está relativizado, nada puede afirmarse sin que sea rebatido. Se llega así al punto, señalado por Baudrillard en la cita copiada al comenzar este apartado, en el que no podemos hablar ni de parodia ni de imitación, sino que se trata de una sustitución de lo real por los signos de lo real ${ }^{29}$, que socava inevitablemente la memoria (en términos de memoria heredada o postmemoria) de la guerra real de 1982 y de las construcciones sociales al respecto.

\footnotetext{
${ }^{28}$ Luego de pactar con los técnicos, cuando Osinde regresa "a la carpa calefaccionada" donde viven los actores mientras no representan su papel en las trincheras, Rodolfo sospecha de él y le dice: "Vos sos un milico loco en serio, culiao" (277). La ficción invade la realidad y “confunde” a los actores.

${ }^{29}$ Es inevitable pensar aquí en una reminiscencia del cuento “Tlön, Uqbar, Orbis Tertius”, de Jorge Luis Borges, donde no solamente la ficción avanza sobre la realidad, sino que también surgen problemas entre lo recordadovivido y lo recordado-imaginado y, por supuesto, acerca del valor de verdad de las informaciones que circulan. La ficción de Borges se basa en una enciclopedia, la de Vanoli en una internet que, como quisieron los enciclopedistas, lo contiene todo, pero por eso mismo adquiere la propiedad de inventarlo todo y, obviamente, de negarlo todo. Ludmer, siguiendo a Baudrillard, arriba a una conclusión similar: "Dice Baudrillard que los modelos o simulacros cibernéticos ya no constituyen una trascendencia o una proyección, ya no constituyen un imaginario en relación con lo real; son ellos mismos anticipación de lo real, y no dejan lugar a ninguna suerte de anticipación ficcional; son inmanentes, y no dejan lugar a ningún tipo de trascendencia imaginaria. El campo abierto es el de la simulación en sentido cibernético, es decir, el de la manipulación de esos modelos, pero entonces nada distingue esta operación de la gestión y de la operación misma de lo real: ya no hay ficción (ıзo, las cursivas son de Ludmer).
} 
Podemos cerrar nuestras observaciones acerca de Cataratas y de la nueva forma de ficcionalizar temas relacionados con Malvinas, con la siguiente reflexión de Drucaroff que intenta establecer cuál es las distancia que media entre las tres generaciones de escritores argentinos que han ocupado nuestra atención a lo largo de las páginas precedentes:

Los nuevos no hacen aquel realismo social que buscaba sobre todo la denuncia, porque sus obras no tienen aquella convicción conmovedora que puede leerse en el realismo anterior: que denunciar va a servir. Al contrario, su lucidez es saber que denunciar es hoy otro show televisivo. Por eso, las representaciones del lumpenaje y la barbarie no se hacen desde la incomprensión pero sí desde la falta de certezas (2OII: 207, las cursivas son nuestras).

\section{Conclusiones}

Hemos comenzado nuestro recorrido recuperando una disputa generacional que intentamos desmontar a partir de diversos testimonios críticos y también a partir de elucidaciones basadas en la capacidad explicativa que el sostenimiento de esa disputa podía asegurar. En base a esa polémica entre Feiling y Soriano, consideramos la posibilidad de abordar el tema Malvinas a partir de un famoso cuento de Juan Forn, donde podía volver a encontrarse un elemento que identificamos como una suerte de leit motiv en el tratamiento del tema: la hipocresía y, sumada a ella, la simulación que nos derivaba directamente hacia la idea del delito.

Este es un aspecto que permitió trazar una línea que se movía dentro del ámbito de lo intrageneracional como hacia la dimensión de lo intergeneracional. La inclusión de "Memorándum Almazán” en la serie permitía también revisitar la hipocresía respecto del problema Malvinas, que se aborda en las otras ficciones, como un continuum de delitos superpuestos, que parten de la invocación de conceptos que apelan a lo emotivo (como la idea de patria) para justificar el sacrificio masivo de jóvenes conscriptos por parte de la dictadura, arribando luego a la simulación de veteranía como un intento individual de aprovechar esa catástrofe y la culpa colectiva que generó, en beneficio propio. Pero en este punto el círculo del delito se cerraba sobre sí mismo, porque nuevamente remitía a la idea del absurdo de la guerra y de sus principios motores.

Siguiendo el esquema generacional trazado, una posibilidad abordaje era la que ensaya Hernán Vanoli en Cataratas quien, de acuerdo a las características señaladas por Drucaroff en su estudio sobre la Nueva Novela Argentina, resignificaba la guerra de 1982 a través de una supuesta Segunda Guerra, lo que terminaba por convertir todo en una ficción. Tanto la guerra como la supervivencia a la misma eran parte de un relato y ya no había que simular la veteranía, sino construir una veteranía real a partir de la ficción generada por los elementos de poder de la sociedad capitalista. El resultado, prácticamente, es el mismo: veteranos cuyos cuerpos y mentes no resisten, se quiebran (están perturbados), veteranos que son a la vez compadecidos y expulsados (o encerrados). 
Después de ese recorrido podemos hacer nuestras, una vez más, las palabras de Josefina Ludmer cuando asegura que "la simulación es un objeto privilegiado porque es el lugar donde hay una disputa sobre la representación, y también un debate político. Es una teoría de la representación y de la resistencia" (2OII: I23).

Es justamente esa disputa y ese debate, en torno al eje de Malvinas, el que hemos intentado reflejar a través de las ficciones con simuladores y con simulaciones. Es una obviedad, a esta altura, señalar que se trata de un tema que está lejos de ser clausurado. Lo que parece ser menos obvio, sin embargo, es que si se quiere avanzar en tal debate hay que dejar atrás más de tres décadas de la cultura del nacionalismo estrecho y del sentimentalismo lastimero que florecen cada vez que se trata este asunto. Soriano, Forn, Feiling y Vanoli son apenas una muestra de ambas cosas: de que la discusión no está zanjada y de que la literatura tiene mucho campo sobre el cual reflexionar, sin caer ni en el perverso discurso triunfalista ni en el superficialmente culpógeno (y, por lo tanto, doblemente perverso) discurso del lamento. 


\section{Referencias bibliográficas}

- Gramuglio, M. T. (I992). “La construcción de la imagen”. En: H. Tizón; R. Rabanal y M. T. Gramuglio La escritura argentina (pp.35-64). Santa Fe: Universidad Nacional del Litoral / Ediciones de La Cortada.

- Drucaroff, E. (2OII). Los prisioneros de la torre: Política, relatos y jóvenes en la postdictadura. C.A.B.A. i.e. Ciudad Autónoma de Buenos Aires: Emecé.

- Feiling, C. E. (2005). Con toda intención. Buenos Aires: Sudamericana.

- Feiling, C. E. (2007). Los cuatro elementos. Buenos Aires: Norma.

- Forn, J. (1996). Nadar de noche. Barcelona: Planeta.

- Kohan, M.; Blanco, O. e Imperatore, A. (1994) “Trashumantes de neblina, no las hemos de encontrar", en Espacios de Crítica y Producción, ı3, 82-86.

- Kurlat, S. (2006). Para una intelectualidad sin episteme: el devenir de la literatura argentina (1974-1989). Buenos Aires: Corregidor.

-Ludmer, J. (1999). El cuerpo del delito. Un manual. Buenos Aires: Perfil.

- Mantiñan, G. (20I5). "A vos te falta Malvinas" Señales de identidad en el relato testimonial de la guerra de Malvinas (1982-2005). Tesis de maestría. Obtenido el i6 de agosto de 20I6 desde: https://avostefaltamalvinas.files.wordpress.com/20I6/o2/tesis-de-g-mantincc83an.pdf

- Molina, M. E. (2008). “Guerra de Malvinas: la literatura argentina y el discurso autocrítico”. Espéculo, 39 [en línea]. Obtenido el II de noviembre de 2015 en https://www.aacademica.org/maria.elena.molina/I3.

- Rozitchner, L. (20I5). Malvinas: de la guerra sucia a la guerra limpia. Buenos Aires: Biblioteca Nacional.

- Sassi, H. (2006). "A pesar de Shanghai, a pesar de Babel". El interpretador. Literatura, arte, pensamiento, $3^{2}$ [en línea]. Obtenido el 20 de febrero de 2016 en http://biblioteca. cefyl.net/node/ı6r64. Publicado originalmente en Pensamiento de los confines $n^{\circ}$ I8, junio de 2006.

- Soriano, O. (1995). A sus plantas rendido un león. Buenos Aires: Norma. 
- Szurmuk, M. (2008). “Usos de la postmemoria: Lenta biografía de Sergio Cheifec”. En: I. Rodríguez I. y Szurmuk, M. (Ed.). Memoria y ciudadanía (pp. 3I-32O). Santiago de Chile: Editorial Cuartopropio.

- Vanoli, H. (20I5). Cataratas. Buenos Aires: Literatura Random House.

- Vitullo, J. (2012). Islas imaginadas. La Guerra de Malvinas en la literatura y el cine argentinos. Buenos Aires: Corregidor. 